\title{
Probing the Interaction Between a Surfactant-Cobalt(III) Complex and Bovine Serum Albumin
}

\author{
Rajendran Senthil Kumar • Hubert van den Bergh • \\ Georges Wagnières
}

Received: 23 February 2011 / Accepted: 11 May 2011 / Published online: 8 February 2012

(C) Springer Science+Business Media, LLC 2012

\begin{abstract}
The mechanism of binding of the surfactant-cobalt(III) complex, cis-[Co(phen $)_{2}$ $\left.\left(\mathrm{C}_{14} \mathrm{H}_{29} \mathrm{NH}_{2}\right) \mathrm{Cl}\right]\left(\mathrm{ClO}_{4}\right)_{2} \cdot 3 \mathrm{H}_{2} \mathrm{O}$ (phen = 1,10-phenanthroline, $\mathrm{C}_{14} \mathrm{H}_{29} \mathrm{NH}_{2}=$ tetradecylamine) with bovine serum albumin (BSA) was investigated by UV-vis absorption, circular dichroism (CD) and fluorescence spectroscopic techniques. The results of fluorescence titration revealed that the surfactant-cobalt(III) complex quenched the intrinsic fluorescence of BSA through a combination of static and dynamic quenching. The apparent binding constant $\left(K_{\mathrm{a}}\right)$ and number of binding sites $(n)$ were calculated below and above the critical micelle concentration (CMC). The thermodynamic parameters determined by the van't Hoff analysis of the constants $\left(\Delta H^{\circ}=14.87 \mathrm{~kJ} \cdot \mathrm{mol}^{-1} ; \Delta S^{\circ}=152.88 \mathrm{~J} \cdot \mathrm{mol}^{-1} \cdot \mathrm{K}^{-1}\right.$ below the $\mathrm{CMC}$ and $25.70 \mathrm{~kJ} \cdot \mathrm{mol}^{-1}$ and $243.14 \mathrm{~J} \cdot \mathrm{mol}^{-1} \cdot \mathrm{K}^{-1}$, respectively, above the CMC) clearly indicate that the binding is entropy-driven and enthalpically disfavored. Based on Förster's theory of non-radiation energy transfer, the binding distance, $r$, between donor (BSA) and the acceptor (surfactant-cobalt(III) complex) was evaluated. UV-vis, CD and synchronous fluorescence spectral results showed that the binding of the surfactant-cobalt(III) complex to BSA induced conformational changes in BSA.
\end{abstract}

Keywords Metallosurfactant · Bovine serum albumin · Fluorescence spectroscopy · Circular dichroism

\section{Introduction}

Proteins are important chemical substances in our life and are the major target of many types of medicine in the body. Protein-metal complex/drug interactions have aroused great interest in recent years [1-3]. Investigating the binding of metal complex/drugs to proteins can provide useful information of the structural features that determine the therapeutic effectiveness of drugs. Bovine serum albumin (BSA) is a model globular protein because its

R. Senthil Kumar $(\bowtie) \cdot H$. van den Bergh $\cdot$ G. Wagnières Medical Photonics Group, ISIC, Ecole Polytechnique Fédérale de Lausanne (EPFL), 1015 Lausanne, Switzerland e-mail: biosen81@gmail.com 
Fig. 1 Structure of cis-[Co(phen $\left.)_{2}\left(\mathrm{C}_{14} \mathrm{H}_{29} \mathrm{NH}_{2}\right) \mathrm{Cl}\right]^{2+}$

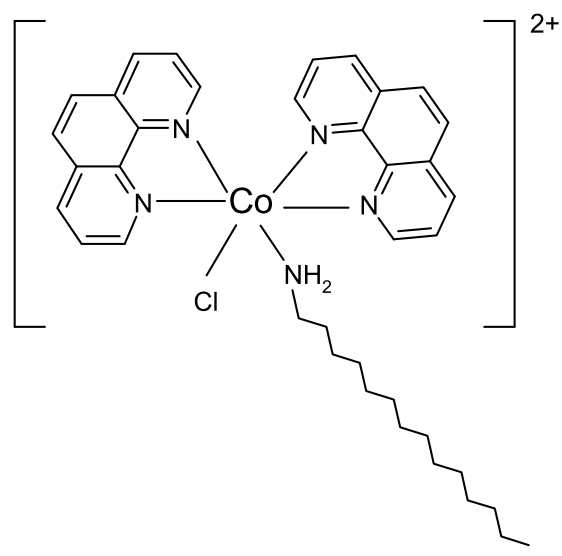

structure and physicochemical properties are well characterized [4]. It is an ideal protein for intrinsic fluorescence measurement due to the presence of two tryptophan (Trp) residues. It is also the main protein contributing to the colloid osmotic pressure of the blood [5]. It is used as a reference in clinical analysis and biochemistry research because of its stability, water solubility and its wide capacity to bind bio-organic/inorganic components. Binding studies with BSA find broad and significant applications in the area of rational drug design as many pharmaceuticals are rendered less effective or entirely ineffective by virtue of their interaction with serum albumin.

Surfactants are schizophrenic molecules; the opposing character of the hydrophilic (headgroup) and hydrophobic (tail) moieties leads to a propensity to adsorb at surfaces"surface activity" - and the spontaneous formation of rather complex but well-defined structures-“self-assembly". Surfactants are ubiquitous in everyday materials, but until recently their role was derived from a physical function-wetting, solubilization, etc.- - rather than any chemical function. Whilst the functions of transition metal ions immobilized within biological membranes have long been an area of intense study [6], the study of interfacebound metals in purely synthetic systems is a relatively new subject area in colloid science. In the metallosurfactant (i.e. surfactant-metal complex) class of amphiphiles, the incorporation of transition metal (d- or f-block) ions into the headgroup introduces into the molecule not only chemical functionality, such as Lewis acidity and redox activity, but also physical properties including color, paramagnetism or fluorescence, and this functionality may be constrained at interfaces by virtue of the inherent surface activity or self-assembly characteristics of the amphiphilic structure of the metallosurfactant.

Surfactants can be broadly classified into those which bind and initiate protein unfolding, i.e. denaturing surfactants and those that only bind leaving the tertiary structure of the protein intact. Many studies have been devoted to the study of the interaction of BSA with surfactants such as CTAB, SDS, and Triton X-100 [7-10] but no attention has been paid to metallosurfactants. We have been interested in the synthesis, micelle-forming and DNA binding properties of several cobalt(III) complexes containing lipophilic ligands [11-13]. To the best of our knowledge no previous study of the interaction of BSA with a metallosurfactant is available. In this paper, we have studied the interaction between the surfactantcobalt(III) complex (Fig. 1) with BSA, using absorption and fluorescence spectroscopies. The binding mechanism between the surfactant-cobalt(III) complex and BSA, including the binding parameters, thermodynamic functions, the binding distances and the effect of the surfactant-cobalt(III) complex upon the conformation of BSA were investigated. 


\section{Materials and Methods}

\subsection{Materials}

The procedure for synthesis of the surfactant-cobalt(III) complex of the present study are as reported in our earlier work [13]. Bovine serum albumin was purchased from Sigma-Aldrich Chemie $\mathrm{GmbH}$. The samples were dissolved in Tris- $\mathrm{HCl}$ buffer solution $\left(0.05 \mathrm{~mol} \cdot \mathrm{L}^{-1}\right.$ Tris, $\left.0.15 \mathrm{~mol} \cdot \mathrm{L}^{-1} \mathrm{NaCl}, \mathrm{pH}=7.4 \pm 0.1\right)$. Milli-Q water was used to prepare the solutions.

\subsection{Methods}

The CMC values of the surfactant-cobalt(III) complex, cis-[Co(phen $\left.)_{2}\left(\mathrm{C}_{14} \mathrm{H}_{29} \mathrm{NH}_{2}\right) \mathrm{Cl}\right]-$ $\left(\mathrm{ClO}_{4}\right)_{2} \cdot 3 \mathrm{H}_{2} \mathrm{O}$, at different temperatures are $6.38 \times 10^{-5} \mathrm{~mol} \cdot \mathrm{L}^{-1}(298 \mathrm{~K}), 6.45 \times 10^{-5} \mathrm{~mol}$. $\mathrm{L}^{-1}(308 \mathrm{~K}), 6.94 \times 10^{-5} \mathrm{~mol} \cdot \mathrm{L}^{-1}(318 \mathrm{~K})$ and $7.43 \times 10^{-5} \mathrm{~mol} \cdot \mathrm{L}^{-1}(328 \mathrm{~K})$ [13]. UV-vis absorption spectra were recorded, using a Cary $500 \mathrm{UV}$-vis spectrophotometer, in the range 200-800 nm. Absorption titration experiments were carried out by keeping the concentration of BSA constant $\left(1 \times 10^{-5} \mathrm{~mol} \cdot \mathrm{L}^{-1}\right)$ while varying the surfactant-cobalt(III) complex concentration from 0 to $25 \times 10^{-6} \mathrm{~mol} \cdot \mathrm{L}^{-1}$ (below the $\mathrm{CMC}$ ) and 7 to $30 \times 10^{-4} \mathrm{~mol} \cdot \mathrm{L}^{-1}$ (above the $\mathrm{CMC}$ ). The fluorescence quenching measurements and synchronous spectra were carried out in a Perkin Elmer LS 50B Luminescence spectrometer equipped with a $1 \mathrm{~cm}$ quartz cell and a thermostatic bath (Varian Cary Peltier System). The concentration of BSA was kept constant $\left(1 \times 10^{-5} \mathrm{~mol} \cdot \mathrm{L}^{-1}\right)$ while varying the surfactant-cobalt(III) complex concentration from 0 to $25 \times 10^{-6} \mathrm{~mol} \cdot \mathrm{L}^{-1} \mathrm{~mol} \cdot \mathrm{L}^{-1}$ (below the $\mathrm{CMC}$ ) and 7 to $30 \times 10^{-4} \mathrm{~mol} \cdot \mathrm{L}^{-1}$ (above the CMC) at four different temperatures $(292,298,304,310 \mathrm{~K})$. The excitation wavelength was $280 \mathrm{~nm}$ and the emission was monitored at $340 \mathrm{~nm}$. The width of both excitation and emission slits was set at $5 \mathrm{~nm}$. The synchronous fluorescence spectra were recorded at $\Delta \lambda=15$ and $60 \mathrm{~nm}$. CD spectra were recorded on Jasco J-810 spectropolarimeter using a $0.1 \mathrm{~cm}$ cell, at room temperature. Scans were made from 190 to $250 \mathrm{~nm}$ and the speed of $200 \mathrm{~nm} \cdot \mathrm{min}^{-1}$. Spectra of appropriate buffer solutions, run under the same conditions, were taken as blanks and subtracted from the sample spectra.

\section{Results and Discussion}

\subsection{Analysis of Fluorescence Quenching}

The BSA molecule has two tryptophan residues that possess intrinsic fluorescence: Trp-134 in the first sub-domain IB of the albumin molecule and Trp-212 in sub-domain IIA. Trp-212 is located within a hydrophobic binding pocket of the protein and Trp-134 is located on the surface of the albumin molecule [14]. A valuable feature of the intrinsic fluorescence of the protein is the high sensitivity of tryptophan to its local environment. Changes in the emission spectrum of tryptophan are common in response to protein conformational transitions, subunit association, substrate binding or denaturation [15]. So, the intrinsic fluorescence of the protein can provide considerable information about their structure and dynamics, and is often considered in the study of protein folding and association reactions.

The interaction of surfactant-cobalt(III) complex with BSA was evaluated by monitoring the intrinsic fluorescence intensity changes of BSA upon addition of the surfactantcobalt(III) complex. Fluorescence spectra of BSA in the absence and in the presence of the surfactant-cobalt(III) complex (below and above the CMC) are shown in Fig. 2. As the 

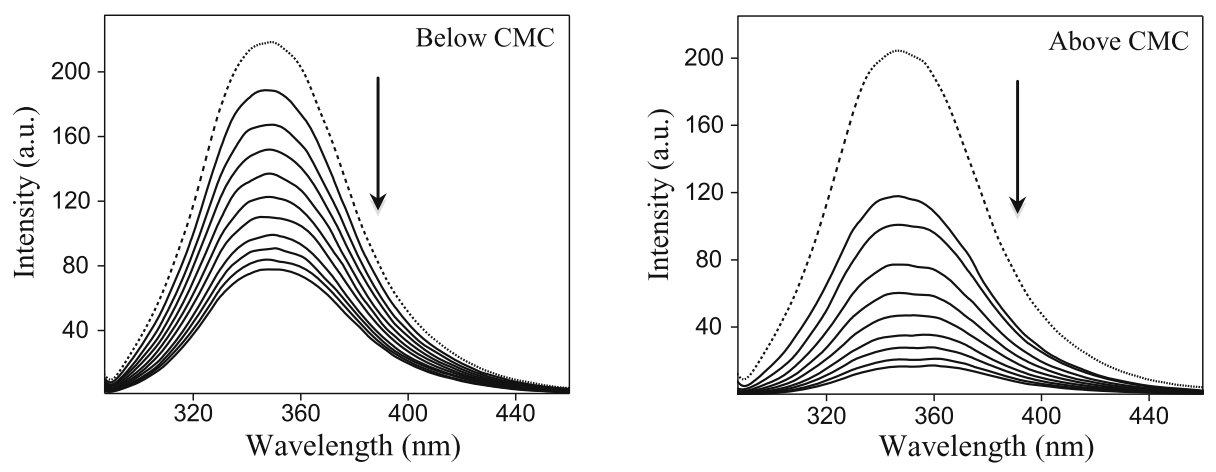

Fig. 2 Emission spectra of BSA in the absence (dotted lines) and in the presence of surfactant-cobalt(III) complex (solid lines). [BSA] $=10 \mu \mathrm{mol} \cdot \mathrm{L}^{-1}$, [surfactant-cobalt(III)] $=2-25 \mu \mathrm{mol} \cdot \mathrm{L}^{-1}$ (below the CMC) and $0.07-0.3 \mathrm{mmol} \cdot \mathrm{L}^{-1}$ (above the $C M C$ ). Arrow shows intensity changes upon increasing surfactant-cobalt(III) complex concentrations

data show, the fluorescence intensity of BSA decreased gradually with increasing concentration of the surfactant-cobalt(III) complex, which indicates that the surfactant-cobalt(III) complex can bind to BSA.

Quenching can appear as a result of various inter and intramolecular interaction, including molecular collisions (dynamic quenching), complex formation (static quenching), energy transfer and/or conformational changes [16]. Therefore, quenching of the intrinsic BSA fluorescence by the surfactant-cobalt(III) complex offers information on the binding process. Fluorescence quenching is described by the Stern-Volmer equation [17]:

$$
\frac{F_{0}}{F}=1+K_{\mathrm{sv}}[\mathrm{Q}]
$$

where $F_{0}$ and $F$ are the fluorescence intensities of BSA in the absence and presence of the quencher, respectively. $K_{\mathrm{sv}}$ is the Stern-Volmer quenching constant, and [Q] is the concentration of quencher. Stern-Volmer plots of BSA with the surfactant-cobalt(III) complex at below and above the CMC are shown in Fig. 3. Below the CMC, the Stern-Volmer plot is linear whereas, above the CMC, the plot shows a positive deviation (concave towards the $y$ axis), suggesting the presence of a combination of static and dynamic quenching by the same fluorophore. According to Eftink and Ghiron [18, 19], the upward curvature in the Stern-Volmer plot indicates that an additional static quenching takes place near the subdomain(s) where tryptophan residues are located. Thus, the positive deviation above the CMC is due to the presence of a quencher molecule in the micellar cage of the fluorophores at the moment of excitation.

In order to calculate the $K_{\mathrm{sv}}$ value of the surfactant-cobalt(III) complex at above the CMC, a modified Stern-Volmer equation that describes quenching data for both dynamic and as static quenching was applied [17]:

$$
\frac{F_{0}}{F}=1+K_{\text {sv }}[\mathrm{Q}] \exp (V[\mathrm{Q}])
$$

where $V$ is the static quenching constant and the value of $V$ can be obtained from Eq. 2 by plotting $\left(F_{0} / F-1\right) / \exp (V[\mathrm{Q}])$ versus [Q] for varying $V$ until a linear plot is acquired. The $K_{\text {sv }}$ value can be then obtained from slope of the $\left(F_{0} / F-1\right) / \exp (V[\mathrm{Q}])$ versus [Q] plot. Values of $V$ and $K_{\mathrm{sv}}$ at four different temperatures (292, 298, 304 and $\left.310 \mathrm{~K}\right)$ are presented 
Fig. 3 Stern-Volmer and modified Stern-Volmer plots of the surfactant-cobalt(III) complex at below and above the $C M C(T=292 \mathrm{~K})$ with BSA

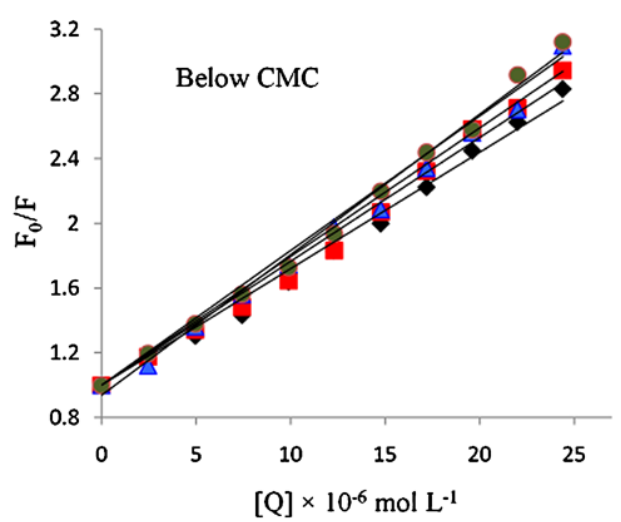

$292 \mathrm{~K}$

- $298 \mathrm{~K}$

$\triangle 304 \mathrm{~K}$

- $310 \mathrm{~K}$

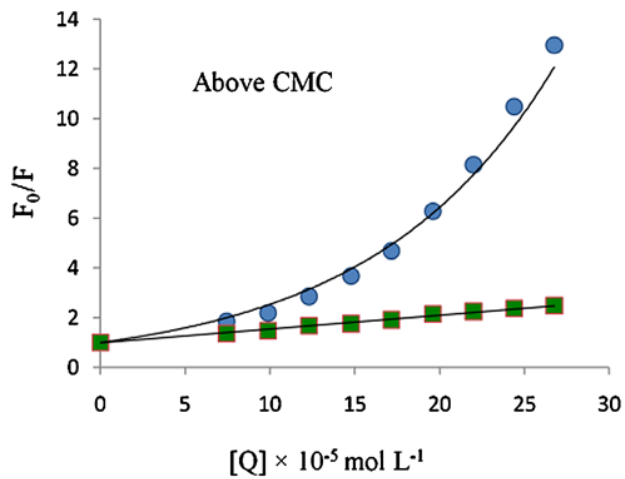

O unmodified

Eodified

Table 1 Stern-Volmer quenching constants for the interaction of the surfactant-cobalt(III) complex with BSA at different temperatures

\begin{tabular}{|c|c|c|c|c|c|c|c|}
\hline \multirow{2}{*}{$\begin{array}{l}T \\
(\mathrm{~K})\end{array}$} & \multicolumn{2}{|c|}{$K_{\mathrm{SV}}\left(\mathrm{L} \cdot \mathrm{mol}^{-1}\right)$} & \multicolumn{2}{|c|}{$k_{\mathrm{q}}\left(\mathrm{L} \cdot \mathrm{mol}^{-1} \cdot \mathrm{s}^{-1}\right)$} & \multirow{2}{*}{$\begin{array}{l}V\left(\mathrm{~L} \cdot \mathrm{mol}^{-1}\right) \\
\text { Above } \\
\text { CMC } \\
\left(\times 10^{3}\right)\end{array}$} & \multicolumn{2}{|l|}{$R^{\mathrm{a}}$} \\
\hline & $\begin{array}{l}\text { Below } \\
\text { CMC } \\
\left(\times 10^{4}\right)\end{array}$ & $\begin{array}{l}\text { Above } \\
\text { CMC } \\
\left(\times 10^{3}\right)\end{array}$ & $\begin{array}{l}\text { Below } \\
\text { CMC } \\
\left(\times 10^{12}\right)\end{array}$ & $\begin{array}{l}\text { Above } \\
\text { CMC } \\
\left(\times 10^{11}\right)\end{array}$ & & $\begin{array}{l}\text { Below } \\
\text { CMC }\end{array}$ & $\begin{array}{l}\text { Above } \\
\text { CMC }\end{array}$ \\
\hline 292 & 7.19 & 5.55 & 7.19 & 5.55 & 9.31 & 0.9909 & 0.9904 \\
\hline 298 & 7.65 & 5.21 & 7.65 & 5.21 & 8.69 & 0.9901 & 0.9910 \\
\hline 304 & 7.96 & 4.34 & 7.96 & 4.34 & 8.52 & 0.9902 & 0.9964 \\
\hline 310 & 8.33 & 3.81 & 8.33 & 3.81 & 8.35 & 0.9916 & 0.9908 \\
\hline
\end{tabular}

${ }^{\text {a }} R$ is the correlation coefficient

in Table 1. The Stern-Volmer quenching constant increases with increasing temperature at and below the CMC but decreases above the CMC.

As for a bimolecular quenching process, Eq. 3 is employed for the evaluation of the quenching rate constant $k_{\mathrm{q}}$ :

$$
k_{\mathrm{q}}=\frac{K_{\mathrm{SV}}}{\tau_{0}}
$$


Table 2 Binding constants and number of binding sites of the surfactant-cobalt(III) complex-BSA at different temperatures

\begin{tabular}{|c|c|c|c|c|c|c|}
\hline \multirow{2}{*}{$\begin{array}{l}T \\
(\mathrm{~K})\end{array}$} & \multicolumn{2}{|c|}{$K_{\mathrm{a}}\left(\mathrm{L} \cdot \mathrm{mol}^{-1}\right)$} & \multicolumn{2}{|l|}{$n$} & \multicolumn{2}{|l|}{$R^{\mathrm{a}}$} \\
\hline & $\begin{array}{l}\text { Below } \\
\text { CMC } \\
\left(\times 10^{5}\right)\end{array}$ & $\begin{array}{l}\text { Above } \\
\text { CMC } \\
\left(\times 10^{8}\right)\end{array}$ & $\begin{array}{l}\text { Below } \\
\text { CMC }\end{array}$ & $\begin{array}{l}\text { Above } \\
\text { CMC }\end{array}$ & $\begin{array}{l}\text { Below } \\
\text { CMC }\end{array}$ & $\begin{array}{l}\text { Above } \\
\text { CMC }\end{array}$ \\
\hline 292 & 2.15 & 1.15 & 1.102 & 1.973 & 0.9965 & 0.9932 \\
\hline 298 & 2.38 & 1.83 & 1.105 & 2.046 & 0.9985 & 0.9914 \\
\hline 304 & 2.63 & 1.90 & 1.109 & 2.056 & 0.9971 & 0.9942 \\
\hline 310 & 3.09 & 2.24 & 1.121 & 2.080 & 0.9978 & 0.9976 \\
\hline
\end{tabular}

${ }^{\text {a }} R$ is the correlation coefficient for the van't Hoff plot

where $k_{\mathrm{q}}$ is the quenching rate constant of the biomolecule, and $\tau_{0}$ is the average lifetime of the biomolecule without quencher. The value of $\tau_{0}$ of the biopolymer is $10^{-8} \mathrm{~s}^{-1}$ [20]. The $k_{\mathrm{q}}$ value is thus calculated to be of the order of $10^{12} \mathrm{~L} \cdot \mathrm{mol}^{-1} \cdot \mathrm{s}^{-1}$ (below the CMC) and $10^{10} \mathrm{~L} \cdot \mathrm{mol}^{-1} \cdot \mathrm{s}^{-1}$ (above the CMC). Futhermore, the maximum diffusion collision quenching rate constant, $k_{\mathrm{q}}$, of various kinds of quenchers with the biopolymer is $2 \times$ $10^{10} \mathrm{~L} \cdot \mathrm{mol}^{-1} \cdot \mathrm{s}^{-1}[20]$. However, the rate constants for the quenching of BSA caused by the surfactant-cobalt(III) complex are higher than this value. This supports our assertion that complex formation plays a significant role in this quenching process.

\subsection{Analysis of Binding Equilibria}

When drug molecules bind independently to a set of equivalent sites on a macromolecule, the equilibrium between free and bound molecules is given by the Eq. 4 [21]:

$$
\log _{10} \frac{F_{0}-F}{F}=\log _{10} K_{\mathrm{a}}+n \log _{10}[\mathrm{Q}]
$$

where $K_{\mathrm{a}}$ is the apparent binding constant of the surfactant-cobalt(III) complex with BSA and $n$ is the number of binding sites per albumin molecule, which can be determined by the slope and the intercept of the double logarithm regression curve of $\log _{10}\left(\left(F_{0}-F\right) / F\right)$ versus $\log _{10}[\mathrm{Q}]$ based on Eq. 4. We have calculated the apparent binding constant and number of binding site values for our surfactant-cobalt(III) complex below and above the CMC. The values are shown in Table 2 . The table shows that the binding constants below the CMC are lower than those above the $\mathrm{CMC}$ and also that the binding constant value increases with increasing temperature for a given system. This is because of the higher hydrophobicity and micelle formation of the surfactant-cobalt(III) complex above the CMC. Recently, we have reported that the critical micelle concentration (CMC) values of the surfactant-cobalt(III) complexes increase with increasing the temperature [11-13]. This behavior may be related to two competitive effects. Firstly, a temperature increase causes a decrease in hydration in the hydrophilic group, which favors micellization. Secondly, a temperature increase also disrupts the water surrounding the hydrophobic group and this retards micellization. The relative magnitude of these two opposing effect will determine the $\mathrm{CMC}$ behavior. The number of binding sites $(n)$ below the CMC is approximately equal to 1 , indicating that there is one class of binding site, whereas above the CMC the value of $n$ is approximately 2, which indicates that there is more than one class of binding site for the surfactant-cobalt(III) complex with BSA. 
Fig. 4 Van't Hoff plot of the BSA-surfactant-cobalt(III) complex at below and above the $C M C$
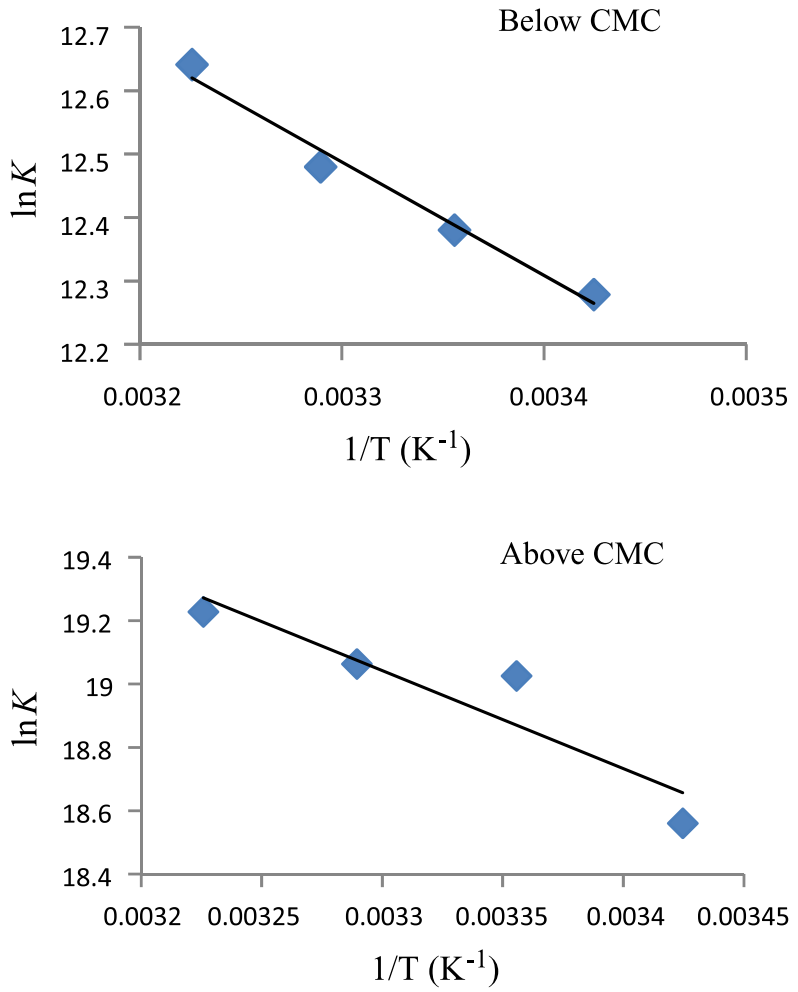

\subsection{The Binding Force Between the Surfactant-Cobalt(III) Complex and BSA}

The forces acting between a pharmaceutical and biomolecule include hydrophobic forces, electrostatic interactions, van der Waals interactions, hydrogen bonds, etc. If the temperature changes little, the reaction enthalpy change is regarded as a constant. In order to explore the interaction of the surfactant-cobalt(III) complex with BSA, thermodynamic parameters were calculated from the van't Hoff equation and corresponding thermodynamic functions based on the temperature effect:

$$
\ln K=-\frac{\Delta H^{\circ}}{R T}+\frac{\Delta S^{\circ}}{R}
$$

where $K$ is the analog to the associative binding constants corresponding to various temperatures, and $R$ is the gas constant. The enthalpy change $\left(\Delta H^{\circ}\right)$ can be calculated from the slope of the van't Hoff relationship (Fig. 4). The Gibbs energy change $\left(\Delta G^{\circ}\right)$ was consequently obtained according to the following equation:

$$
\Delta G^{\circ}=\Delta H^{\circ}-T \Delta S^{\circ}=-R T \ln K
$$

Values of $\Delta G^{\circ}, \Delta H^{\circ}$, and $\Delta S^{\circ}$ are summarized and listed in Table 3. The negative $\Delta G^{\circ}$ values indicate that the binding process is favorable. Ross and Subramanian [22] have characterized the sign and magnitude of the thermodynamic parameter associated with various individual kinds of interaction that may take place in the protein association processes. From the point of view of the water structure, the positive $\Delta H^{\circ}$ and $\Delta S^{\circ}$ values are frequently taken as typical evidence for hydrophobic interaction. Futhermore, specific electrostatic interactions between ionic species in aqueous solution are characterized by a negative $\Delta H^{\circ}$ 
Table 3 Thermodynamic parameters for the binding of the surfactant-cobalt(III) complex to BSA

\begin{tabular}{|c|c|c|c|c|c|c|}
\hline \multirow{2}{*}{$\begin{array}{l}T \\
(\mathrm{~K})\end{array}$} & \multicolumn{2}{|c|}{$\Delta H^{\circ}\left(\mathrm{kJ} \cdot \mathrm{mol}^{-1}\right)$} & \multicolumn{2}{|c|}{$\Delta G^{\circ}\left(\mathrm{kJ} \cdot \mathrm{mol}^{-1}\right)$} & \multicolumn{2}{|c|}{$\Delta S^{\circ}\left(\mathrm{J} \cdot \mathrm{mol}^{-1} \cdot \mathrm{K}^{-1}\right)$} \\
\hline & Below CMC & Above CMC & Below CMC & Above CMC & Below CMC & Above CMC \\
\hline 292 & & & -29.81 & -45.06 & & \\
\hline 298 & 14.87 & 25.70 & -30.67 & -47.14 & 152.88 & 243.14 \\
\hline 304 & & & -31.54 & -48.18 & & \\
\hline 310 & & & -32.58 & -49.55 & & \\
\hline
\end{tabular}

and a positive $\Delta S^{\circ}$ value, while negative entropy changes arise from both van der Waals forces and hydrogen bond formation. Therefore, it can be deduced that the binding force of the surfactant-cobalt(III) complex to BSA is mainly hydrophobic.

\subsection{Energy Transfer from BSA to the Surfactant-Cobalt(III) Complex}

Energy transfer phenomena have wide application in energy conversion processes [23]. According to Förster's non-radiative resonance energy transfer theory [24], a transfer of energy can take place through a direct electrodynamic interaction between the initially excited molecule and its neighbors [25]. The ligand-protein interaction gives rise to energy changes, from which the distance between two interacting molecules can be easily evaluated. The efficiency of an energy transfer, $E$, is related to the distance, $r$, between donor and acceptor by the following equation [26]:

$$
E=1-\frac{F}{F_{0}}=\frac{R_{0}^{6}}{R_{0}^{6}+r^{6}}
$$

where $F$ and $F_{0}$ are the fluorescence intensities of BSA in the presence and absence of surfactant-cobalt(III) complex, $r$ is the distance between donor (BSA) and acceptor (surfactant-cobalt(III) complex). $R_{0}$, the critical distance at which the transfer efficiency equals $50 \%$, is given by the following equation:

$$
R_{0}^{6}=8.8 \times 10^{-25} k^{2} n^{-4} \Phi J
$$

In Eq. 8, $k^{2}$ is the orientation factor of the dipole; $n$ is the refractive index of the medium; $\Phi$ is the fluorescence quantum yield of the donor and $J$ expresses the degree of spectral overlap between the donor emission and the acceptor absorption (Fig. 5) spectra, which can be calculated by the equation:

$$
J=\frac{\sum F(\lambda) \varepsilon(\lambda) \lambda^{4} \Delta \lambda}{\sum F(\lambda) \Delta \lambda}
$$

where $F(\lambda)$ is the fluorescence intensity of the fluorescence donor at wavelength $\lambda$, and $\varepsilon(\lambda)$ is the molar absorption coefficient of the acceptor at wavelength $\lambda$. In the presence case, $k^{2}=2 / 3, n=1.36$ and $\Phi=0.15$ for BSA [4]. Using Eqs. 7-9, we calculate that $J=2.19 \times 10^{-14} \mathrm{~cm}^{3} \cdot \mathrm{L} \cdot \mathrm{mol}^{-1}, E=0.647, R_{0}=2.87 \mathrm{~nm}$ and $r=2.63 \mathrm{~nm}$ (below the $\mathrm{CMC}$ ) and $J=1.308 \times 10^{-16} \mathrm{~cm}^{3} \cdot \mathrm{L} \cdot \mathrm{mol}^{-1}, E=0.922, R_{0}=1.22 \mathrm{~nm}$ and $r=0.99 \mathrm{~nm}$ (above the CMC). The distance between donor and acceptor is less than $8 \mathrm{~nm}$ [27], which implies that the energy transfer from BSA to the surfactant-cobalt(III) complex occurred with high probability, especially above the CMC. 

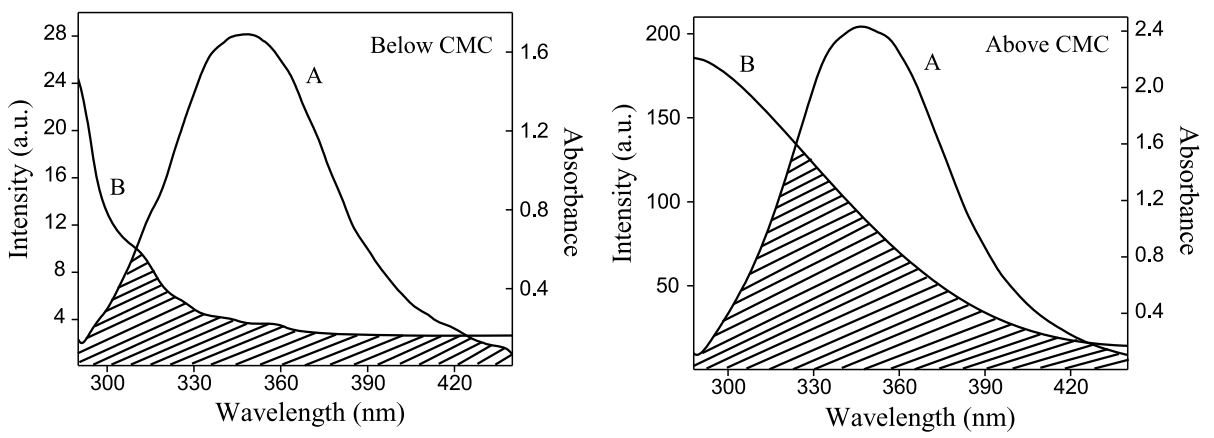

Fig. 5 Spectral overlap between the fluorescence emission spectrum of BSA (A) and UV-vis absorption spectrum of the surfactant-cobalt(III) complex (B) $[$ surfactant-cobalt(III) $]=[\mathrm{BSA}]=1 \mu \mathrm{mol} \cdot \mathrm{L}^{-1}($ below the $C M C$ ) and $1 \mathrm{mmol} \cdot \mathrm{L}^{-1}$ (above the $C M C$ )
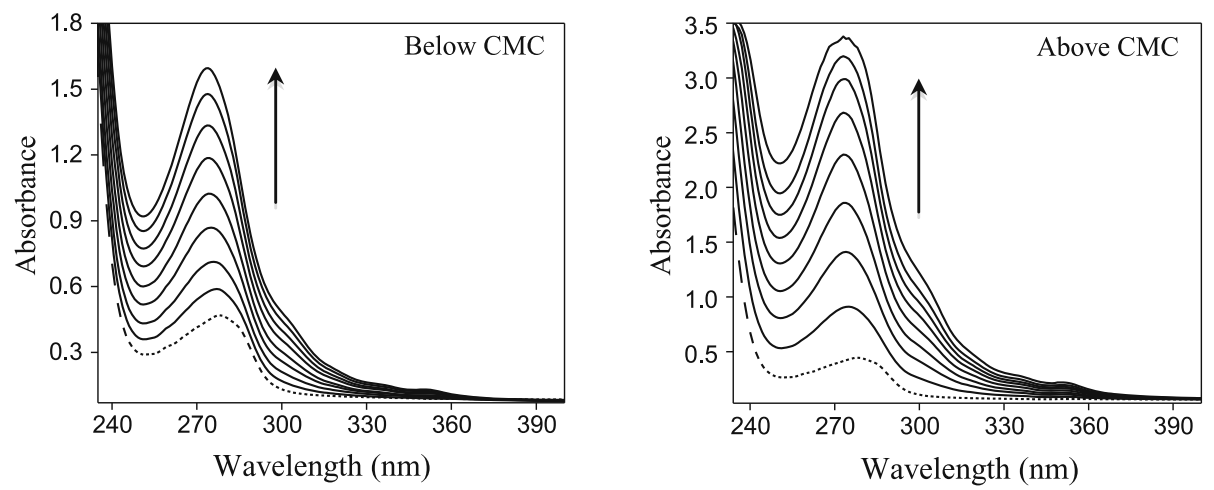

Fig. 6 Absorption spectra of BSA in the absence (dotted lines) and in the presence of increasing amounts of cis-[Co(phen $\left.)_{2}\left(\mathrm{C}_{14} \mathrm{H}_{29} \mathrm{NH}_{2}\right) \mathrm{Cl}\right]\left(\mathrm{ClO}_{4}\right)_{2} \cdot 3 \mathrm{H}_{2} \mathrm{O}$ (solid lines). [BSA] $=10 \mu \mathrm{mol} \cdot \mathrm{L}^{-1}$, [surfactantcobalt(III) $]=2-25 \mu \mathrm{mol} \cdot \mathrm{L}^{-1}$ (below the CMC) and $0.07-0.3 \mathrm{mmol} \cdot \mathrm{L}^{-1}$ (above the CMC). Arrow shows the absorbance changes upon increasing surfactant-cobalt(III) concentrations

\subsection{The Effect of the Surfactant-Cobalt(III) Complex on the BSA Conformation}

\subsubsection{Absorption Spectroscopic Studies}

UV-vis absorption studies were performed to ascertain changes of the secondary structure of BSA and to analyze the interaction affinity between the surfactant-cobalt(III) complex and BSA. It is well known that the absorption of a chromophore is shifted in directions and magnitudes that depend on whether it is transferred to a more hydrophilic or more hydrophobic environment [28]. Figure 6 shows the effect of increasing concentration of the surfactant-cobalt(III) complex on the absorption spectrum of BSA (the absorption spectrum of the surfactant-cobalt(III) complex is shown in Fig. 7). It was observed that the absorption of BSA increased on the addition of the surfactant-cobalt(III) complex. The maximum peak position of surfactant-cobalt(III)-BSA was shifted slightly towards lower wavelengths. The results indicate interaction between surfactant-cobalt(III) complex and BSA and that a ground state complex was formed; the microenvironment around BSA was changed [29]. 


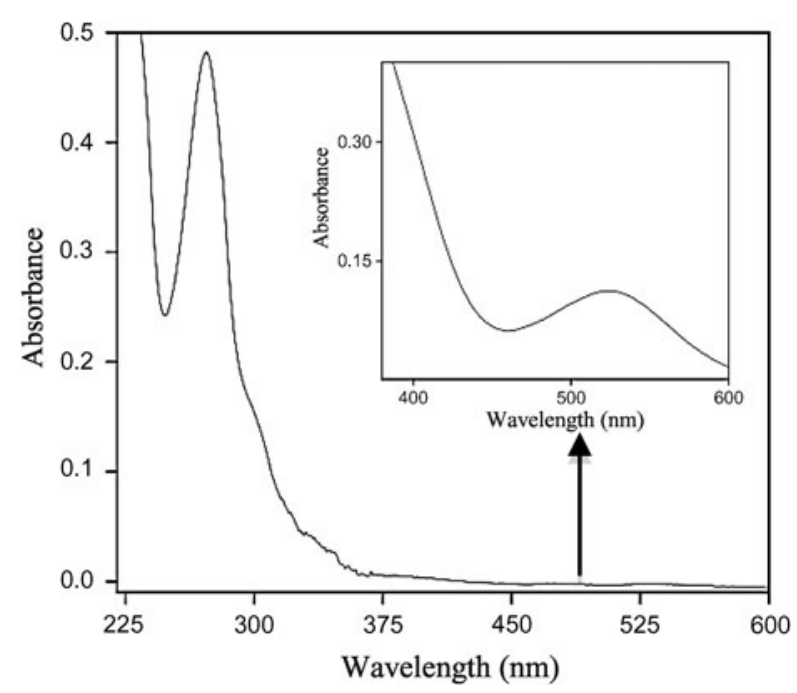

Fig. 7 Absorption spectrum of cis- $\left[\mathrm{Co}(\text { phen })_{2}\left(\mathrm{C}_{14} \mathrm{H}_{29} \mathrm{NH}_{2}\right) \mathrm{Cl}\right]\left(\mathrm{ClO}_{4}\right)_{2} \cdot 3 \mathrm{H}_{2} \mathrm{O}$

\subsubsection{Synchronous Fluorescence Spectroscopic Studies}

It is well known that the fluorescence of BSA comes from the tyrosine, tryptophan and phenylalanine residues. The spectrum of BSA is sensitive to the microenvironment of these chromophores and allows non-intrusive measurements of protein under physiological conditions. In synchronous fluorescence spectroscopy, according to Miller [30], distinction of the difference between excitation wavelength and emission wavelength $(\Delta \lambda)$ reflects the spectra of disparate chromophores; with $\Delta \lambda$ of $60 \mathrm{~nm}$, the synchronous fluorescence of BSA is characteristic of tryptophan residues and with $\Delta \lambda$ of $15 \mathrm{~nm}$ is characteristic of tyrosine.

Figure 8 shows, the synchronous fluorescence spectra of BSA upon addition of the surfactant-cobalt(III) complex (below and above CMC) at $\Delta \lambda=15$ and $60 \mathrm{~nm}$. As shown in Fig. 8, the quenching of the fluorescence intensity of tryptophan residues is stronger than that of the tyrosine residues, suggesting that the tryptophan residues contribute greatly to the quenching of intrinsic fluorescence. Moreover, a red shift of the maximum emission wavelength of tyrosine and tryptophan residues from 286 to $288 \mathrm{~nm}$ below the CMC and 286 to $290 \mathrm{~nm}$ above the CMC indicates that the conformation of BSA changed and the hydrophobicity around both residues increased.

\subsubsection{Circular Dichroism Studies}

To get a deeper insight into the role of the structural changes of BSA with addition of the drug, circular dichroism experiments exploring the secondary structure of the protein affected by the surfactant-cobalt(III) complex were performed. BSA has a high percentage of $\alpha$-helical structure, which shows a characteristic strong double minimum at 222 and $208 \mathrm{~nm}$ [31]. The intensities of the double minimum reflect the amount of helicity of BSA and indicate that BSA contains more than $50 \%$ of $\alpha$-helical structure. Binding of the surfactant-cobalt(III) complex to BSA (Fig. 9) shows a distinct decrease in the band at $222 \mathrm{~nm}$, whereas the band at $208 \mathrm{~nm}$ was completely quenched. The pattern of the CD spectrum is unusual compared with other BSA-drug CD spectra [32-34], which show a distinct 
a

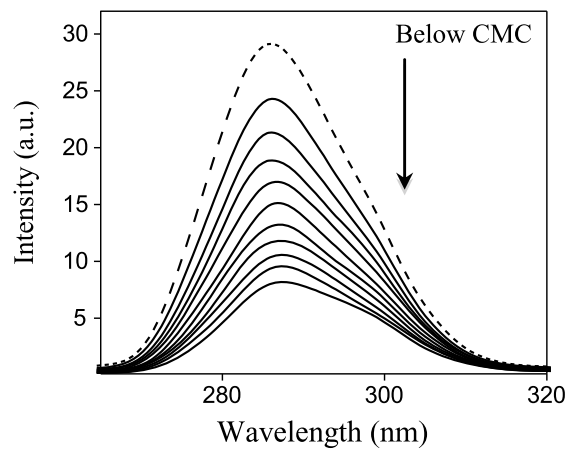

b

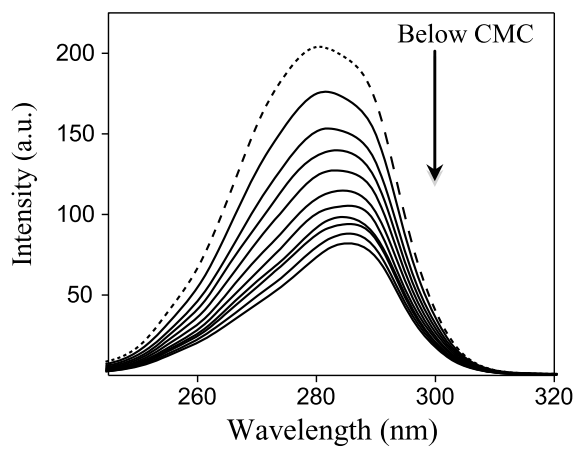

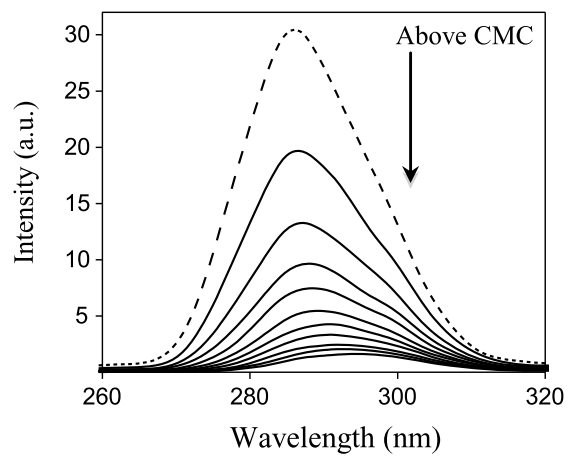

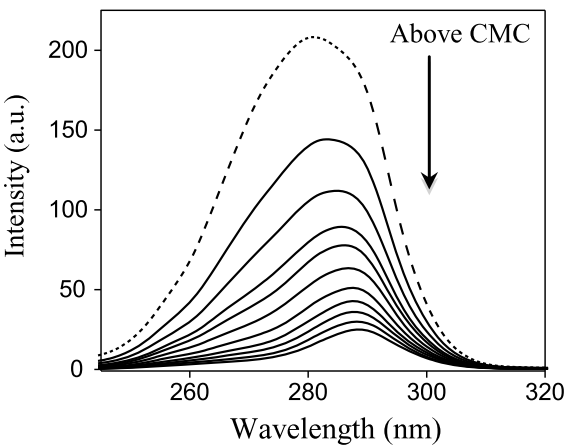

Fig. 8 Synchronous fluorescence spectra of BSA with $\Delta \lambda=15 \mathrm{~nm}$ (a) and 60 (b) in the absence (dotted lines) and in the presence of increasing amounts of surfactant-cobalt(III) complex (solid lines). $[\mathrm{BSA}]=10 \mu \mathrm{mol} \cdot \mathrm{L}^{-1}$, [surfactant-cobalt(III)] $=2-25 \mu \mathrm{mol} \cdot \mathrm{L}^{-1}$ (below the CMC) and 0.07$0.3 \mathrm{mmol} \cdot \mathrm{L}^{-1}$ (above the CMC). Arrows shows the intensity changes upon increasing surfactant-cobalt(III) complex concentrations

Fig. 9 CD spectra of the BSA-surfactant-cobalt(III) complex system in $0.1 \mathrm{~mol} \cdot \mathrm{L}^{-1}$ phosphate buffer of $\mathrm{pH}=7.4$ at room temperature. The BSA concentration was kept fixed at $10 \mu \mathrm{mol} \cdot \mathrm{L}^{-1}$.

Surfactant-cobalt(III)

concentrations were

$10 \mu \mathrm{mol} \cdot \mathrm{L}^{-1}$ (a),

$20 \mu \mathrm{mol} \cdot \mathrm{L}^{-1}$ (b) (below the CMC), $0.1 \mathrm{mmol} \cdot \mathrm{L}^{-1}$ (c) and $0.2 \mathrm{mmol} \cdot \mathrm{L}^{-1}$ (d) (above the CMC)

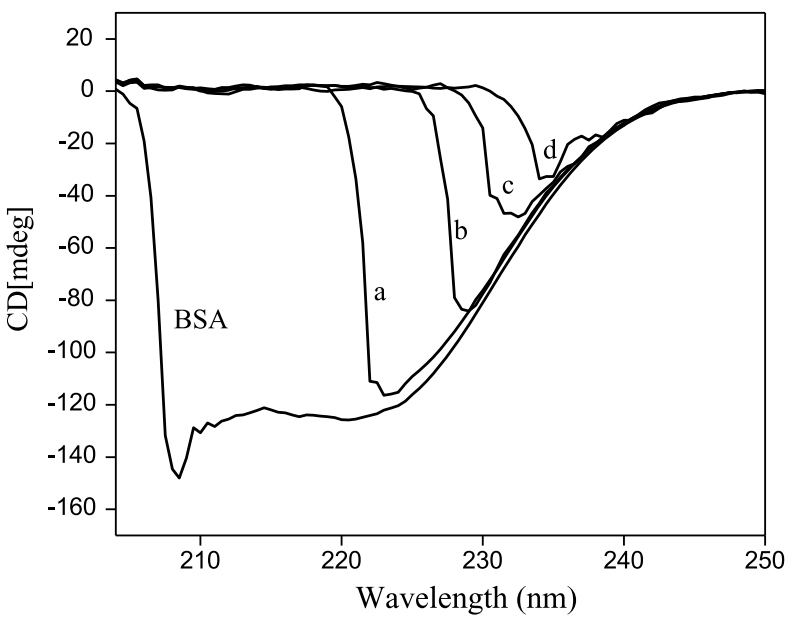


decrease in both negative bands of BSA. We attribute the CD change to an overall decrease in the $\alpha$-helical structure compared to $\beta$-pleated sheet secondary structure [35].

\section{Conclusion}

In the present work, the binding of surfactant-cobalt(III) complex, cis-[Co(phen $)_{2}$ $\left.\left(\mathrm{C}_{14} \mathrm{H}_{29} \mathrm{NH}_{2}\right) \mathrm{Cl}\right]\left(\mathrm{ClO}_{4}\right)_{2} \cdot 3 \mathrm{H}_{2} \mathrm{O}$ to $\mathrm{BSA}$ was studied using spectroscopic techniques under physiological conditions. Various binding parameters have been evaluated. The positive values of thermodynamic parameters $\left(\Delta H^{\circ}\right.$ and $\left.\Delta S^{\circ}\right)$ suggested that the surfactant-cobalt(III) complex is bound to BSA mainly through hydrophobic interactions. The binding distances ( $r=2.63 \mathrm{~nm}$ below the CMC, and $0.99 \mathrm{~nm}$ above the CMC) between BSA and surfactantcobalt(III) complex were obtained using fluorescence resonance energy transfer. The results of synchronous fluorescence spectroscopy and circular dichroism spectra indicated that the conformation of BSA was changed in the presence of the surfactant-cobalt(III) complex.

Acknowledgements The authors gratefully acknowledge a fellowship for Senthil Kumar from the Federal Commission for Scholarships for Foreign Students (FCS) in Switzerland.

\section{References}

1. Gharagozlou, M., Boghaei, D.M.: Interaction of water-soluble amino acid Schiff base complexes with bovine serum albumin: fluorescence and circular dichroism studies. Spectrochim. Acta Part A 71, 16171622 (2008)

2. Zhang, Y.Z., Zhang, X.P., Hou, H.N., Dai, J., Liu, Y.: Study on the interaction between $\mathrm{Cu}(\mathrm{phen})_{3}^{2+}$ and bovine serum albumin by spectroscopic methods. Biol. Trace Elem. Res. 121, 276-287 (2008)

3. Ge, F., Chen, C., Liu, D., Han, B., Xiong, X., Zhao, S.: Study on the interaction between theasinesin and human serum albumin by fluorescence spectroscopy. J. Lumin. 130, 168-173 (2010)

4. He, X.M., Cater, D.C.: Atomic structure and chemistry of human serum albumin. Nature 358, 209-215 (1992)

5. Peters, T. Jr.: All About Albumin. Biochemistry, Genetics, and Medical Applications. Academic Press, San Diego (1996)

6. Griffiths, P.C., Fallis, I.A., Chuenpratoom, T., Watanesk, R.: Metallosurfactants: interfaces and micelles. Adv. Colloid Interface Sci. 122, 107-117 (2006)

7. Diaz, X., Abuin, E., Lissi, E.: Quenching of BSA intrinsic fluorescence by alkylpyridinium cations: its relationship to surfactant-protein association. J. Photochem. Photobiol. A 155, 157-162 (2003)

8. Ding, Y., Shu, Y., Ge, L., Guo, R.: The effect of sodium dodecyl sulfate on the conformation of bovine serum albumin. Colloids Surf. A, Physicochem. Eng. Asp. 298, 163-169 (2004)

9. Valstar, A., Almgren, M., Brown, W.: The interaction of bovine serum albumin with surfactants studied by light scattering. Langmuir 16, 922-927 (2000)

10. Tribout, M., Paredes, S., González-Manas, J.M., Goñi, F.M.: Binding of Triton X-100 to bovine serum albumin as studied by surface tension measurements. J. Biochem. Biophys. Methods 22, 129-133 (1991)

11. Senthil Kumar, R., Arunachalam, S., Periasamy, V.S., Preethy, C.P., Riyasdeen, A., Akbarsha, M.A.: Micellization behaviour, DNA binding, antimicrobial, and cytotoxicity studies of surfactant-cobalt(III) complexes containing di- and tetramine ligands. Aust. J. Chem. 62, 165-175 (2009)

12. Senthil Kumar, R., Arunachalam, S., Periasamy, V.S., Preethy, C.P., Riyasdeen, A., Akbarsha, M.A.: Surfactant-cobalt(III) complexes: synthesis, critical micelle concentration (CMC) determination, DNA binding, antimicrobial and cytotoxicity studies. J. Inorg. Biochem. 103, 117-127 (2009)

13. Senthil Kumar, R., Arunachalam, S.: Synthesis, micellar properties, DNA binding and antimicrobial studies of some surfactant-cobalt(III) complexes. Biophys. Chem. 136, 136-144 (2008)

14. Kragh-Hansen, U.: Molecular aspects of ligand binding to serum albumin. Pharmacol. Rev. 33, 17-53 (1981)

15. Sulkowska, A.: Interaction of drugs with bovine and human serum albumin. J. Mol. Struct. 614, 227-232 (2002)

16. Valeur, B.: Molecular Fluorescence. Principles and Applications. Wiley, New York (2006) 
17. Lakowicz, J.R.: Principles of Fluorescence Spectroscopy, third edn. Springer, New York (2006)

18. Eftink, M.R., Ghiron, C.A.: Fluorescence quenching of indole and model micelle systems. J. Phys. Chem. 80, 486-493 (1976)

19. Eftink, M.R., Ghiron, C.A.: Fluorescence quenching studies with proteins. Anal. Biochem. 114, 199-227 (1981)

20. Lakowicz, J.R., Weber, G.: Quenching of fluorescence by oxygen. Probe for structural fluctuations in macromolecules. Biochemistry 12, 4161-4170 (1973)

21. Feng, X.Z., Jin, R.X., Qu, Y., He, X.W.: Studies on the ion effect on the binding interaction between HP and BSA. Chem. J. Chin. Univ. 17, 866-869 (1996)

22. Ross, P.D., Subramanian, S.: Thermodynamics of protein association reactions: forces contributing to stability. Biochemistry 20, 3096-3102 (1981)

23. Naik, D.B., Moorthy, P.N., Priyadarshini, K.I.: Nonradiative energy transfer from amino coumarin dyes to thiazine dyes in methanolic solutions. Chem. Phys. Lett. 168, 533-538 (1990)

24. Förster, T.: Modern Quantum Chemistry, p. 93. Academic Press, New York (1965)

25. Förster, T.: Intermolecular energy migration and fluorescence. Ann. Phys. 2, 55-75 (1948)

26. Cyril, L., Earl, J.K., Sperry, W.M.: Biochemist's Handbook, p. 84. Kluwer Academic, London (1961)

27. Valeur, B., Brochon, J.C.: New Trends in Fluorescence Spectroscopy. Springer, Berlin (1999)

28. Zhong, W.-Y., Wang, Y.-C., Yu, J.-S., Liang, Y.-Q., Ni, K.-Y., Tu, S.-Z.: The interaction of human serum albumin with a novel antidiabetic agent-SU-118. J. Pharm. Sci. 93, 1039-1046 (2004)

29. Donovan, J.W.: Changes in ultraviolet absorption produced by alteration of protein conformation. J. Biol. Chem. 244, 1961-1967 (1969)

30. Miller, J.N.: Recent advances in molecular luminescence analysis. Proc. Anal. Div. Chem. Soc. 16, 203208 (1979)

31. Quiming, N.S., Vergel, R.B., Nicolas, M.G., Villanueva, J.A.: Interaction of bovine serum albumin and metallothionein. J. Health Sci. 51, 8-15 (2005)

32. Shaikh, S.M.T., Seetharamappa, J., Kandagal, P.B., Manjunatha, D.H., Ashoka, S.: Spectroscopic investigations on the mechanism of interaction of bioactive dye with bovine serum albumin. Dyes Pigments 74, 665-671 (2007)

33. Qu, P., Lu, H., Ding, X., Tao, Y., Lu, Z.: Study on the interaction of 6-thioguanine with bovine serum albumin by spectroscopic techniques. J. Mol. Struct. 920, 172-177 (2009)

34. Shahabadi, N., Maghsudi, M.: Binding studies of a new copper(II) complex containing mixed aliphatic and aromatic dinitrogen ligands with bovine serum albumin using different instrumental methods. J. Mol. Struct. 929, 193-199 (2009)

35. Kelly, S.M., Jess, T.J., Price, N.C.: How to study proteins by circular dichroism. Biochim. Biophys. Acta 1751, 119-139 (2005) 